\title{
Prevalência e fatores de risco para brucelose suína em Mossoró-RN ${ }^{1}$
}

\author{
Alexandro I. Leite ${ }^{2,3 *}$, Wesley A.C. Coelho ${ }^{3}$, Glaucenyra C.P. Silva ${ }^{4}$, Renata F. Santos ${ }^{4}$, \\ Luis A. Mathias ${ }^{4}$ e Iveraldo S. Dutra ${ }^{5}$
}

\begin{abstract}
Leite A.I., Coelho W.A.C., Silva G.C.P., Santos R.F., Mathias L.A. \& Dutra I.S. 2014. [Prevalence and risk factors for brucellosis in pigs in Mossoró-RN.] Prevalência e fatores de risco para Brucelose suína em Mossoró-RN. Pesquisa Veterinária Brasileira 34(6):537-541. Departamento de Ciências Animais, Universidade Federal Rural do Semi-Árido, Av. Francisco Mota 572, Costa e Silva, Mossoró, RN 59625-900, Brazil. E-mail: alex@ufersa.edu.br

The study aimed to determine the prevalence of brucellosis and its risk factors in the pig herd of Mossoró-RN. Comprised a cross-sectional quantitative approach and epidemiological study, where 412 blood samples of pigs from major producers in the municipality were collected and inspection of herds with interviews with producers were conducted. Antibodies to Brucella spp. were detected by the rose Bengal test (RBT) and confirmed by the complement fixation test (CFT). The prevalence of brucellosis in pigs was $27.0 \%$ in the RBT and $17.5 \%$ in the CFT. In $55 \%$ of the surveyed properties there was at least one positive animal, and these prevalence ranged from $6.7 \%$ to $80.0 \%$. Risk factors that were influencing the occurrence of the disease were the presence of rats in the farms, contact with cattle and the young age of the animals. The study results showed that the causative agent of brucellosis was circulating in pigs in the municipality of Mossoró-RN, with high prevalence in the herd and on the properties, indicating the risk of transmission of this zoonosis to humans.
\end{abstract}

INDEX TERMS: Swine health, epidemiology, prevalence, risk factors, Brucella suis, brucellosis.

RESUMO.- A presente pesquisa teve como objetivo determinar a prevalência da brucelose e seus fatores de risco no rebanho suíno de Mossoró/RN. Compreendeu um estudo epidemiológico transversal e de abordagem quantitativa, no qual foram coletadas 412 amostras sanguíneas de suínos provenientes dos principais produtores do município e realizada inspeção das criações com entrevistas aos produtores. Anticorpos anti-Brucella spp. foram detectados pelo teste do antígeno acidificado tamponado (AAT) e con-

\footnotetext{
${ }^{1}$ Recebido em 28 de janeiro de 2014.

Aceito para publicação em 4 de abril de 2014 .

${ }^{2}$ Pós-Graduando em Medicina Veterinária da Faculdade de Ciências Agrária e Veterinária (FCAV), Universidade Estadual Paulista (Unesp), Via de Acesso Prof. Paulo Donato Castellane s/n, Jaboticabal, SP 14884-900, Brasil. *Autor para correspondência: alex@ufersa.edu.br

${ }^{3}$ Departamento de Ciências Animais, Universidade Federal Rural do Semi-Árido (UFERSA), Av. Francisco Mota 572, Costa e Silva, Mossoró, RN 59625-900, Brasil.

${ }^{4}$ Departamento de Medicina Veterinária Preventiva e Reprodução Animal, FCAV-Unesp, Jaboticabal, SP.

${ }^{5}$ Departamento de Apoio, Produção e Saúde Animal, Faculdade de Medicina Veterinária (FMV), Unesp, Rua Clóvis Pestana 763, Jardim Dona Amélia, Araçatuba, SP 16050-680, Brasil. E-mail: isdutra@fmva.unesp.b
}

firmados pela reação de fixação de complemento (RFC). A prevalência da brucelose nos suínos foi de $27,0 \%$ no teste de AAT e 17,5\% na RFC. Em 55\% das propriedades pesquisadas havia pelo menos um animal positivo, e a prevalência nestas variou de $6,7 \%$ a $80,0 \%$. Os fatores de risco que estavam influenciando a ocorrência da doença foram: a presença de ratos nas criações, o contato com bovinos e a faixa etária jovem dos animais. Os resultados do estudo permitiram concluir que o agente etiológico da brucelose estava circulando em suínos do município de Mossoró-RN, com elevada prevalência no rebanho e nas propriedades, evidenciando o risco de transmissão desta zoonose para o homem.

TERMOS DE INDEXAÇÃO: Sanidade suína, epidemiologia, soroprevalência, fatores de risco, Brucella suis, brucelose.

\section{INTRODUÇÃO}

A brucelose é uma doença infectocontagiosa provocada por bactérias do gênero Brucella, que produz infecção crônica nos animais, podendo também infectar o homem. É uma zoonose de distribuição universal que acarreta problemas sanitários e prejuízos econômicos importantes. No homem, 
a doença apresenta um forte componente de caráter ocupacional (Aparicio 2013).

Devido à sua posição evolutiva como um persistente patógeno em várias espécies de hospedeiros, a brucelose continua a ser negligenciada ou subpriorizada em muitas áreas, apesar dos avanços notáveis em ciência, tecnologia e gestão, permanecendo como um importante problema, principalmente entre os pequenos criadores (Plumb et al. 2013).

Em suínos, a brucelose teve uma redução acentuada na sua prevalência devido à tecnificação na exploração comercial dessa espécie, embora focos esporádicos ainda possam ocorrer mesmo em granjas tecnificadas (Mathias 2008). No entanto, a brucelose suína pode representar um risco proporcionalmente maior que a brucelose bovina, pois apresenta um maior grau de patogenicidade para humanos (Brasil 2006).

No Brasil, a doença é prioritariamente contemplada no Programa Nacional de Sanidade Suína (Brasil 2009) por ser de alto poder de difusão, trazer consequências econômicas e/ou sanitárias graves, além da repercussão no comércio internacional, estando inclusa na lista da Organização Mundial de Saúde Animal em vigor no ano de 2014 (OIE 2014).

A maioria das pesquisas de soroprevalência da brucelose suína são estudos pontuais realizados principalmente no Sul e Sudeste do país. No Nordeste, alguns inquéritos foram realizados no Estado do Piauí, na Zona da Mata de Pernambuco e na Região Metropolitana de Natal, Rio Grande do Norte (Ribeiro et al. 2001, Ribeiro 2005, Braga et al. 2013). No entanto, apesar de sua importância, estudos sobre a brucelose em suínos no Nordeste ainda são escassos, principalmente em decorrência dessa exploração ser exercida, em sua maioria, por pequenos produtores e agricultores familiares. Diante do exposto, o presente estudo teve como objetivo determinar a prevalência da brucelose e seus fatores de risco no rebanho suíno de Mossoró-RN.

\section{MATERIAL E MÉTODOS}

O estudo foi desenvolvido no município de Mossoró, localizado na Mesorregião Oeste do Estado do Rio Grande do Norte, com população de 280.314 habitantes. 0 município é o segundo mais populoso, o maior em extensão territorial e concentra o maior rebanho suíno do estado (IBGE 2012a).

A pesquisa compreendeu um estudo epidemiológico transversal e de abordagem quantitativa em que foi determinada a situação da brucelose suína em relação aos fatores de risco para a sua ocorrência. 0 tamanho da amostra foi calculado pela fórmula utilizada em epidemiologia de acordo com o número de animais existentes no município, que era de 6.046 suínos (IBGE 2012b), considerando uma prevalência desconhecida, estimada em $50 \%$, com nível de confiança de $95 \%$ e erro estatístico de $5 \%$ (Thrusfield 2004), o que determinou uma amostra mínima total de 384 animais; assim, foram colhidas 412 amostras.

Para a formação da amostra, buscou-se incluir no estudo animais dos principais produtores de criações comerciais do município, de acordo com informações do Abatedouro Frigorífico Industrial de Mossoró (AFIM) e do Serviço de Inspeção Municipal (SIM), onde foi acompanhada toda a movimentação e o abate de suínos neste estabelecimento durante o primeiro semestre de 2013 e elencados os seus fornecedores. Ao final, contabilizaram-se 20 produtores responsáveis pelo fornecimento de $100 \%$ dos animais abatidos no período.
Assim sendo, a amostragem se deu por conveniência e as amostras de sangue foram colhidas no Abatedouro Frigorífico Industrial de Mossoró, por ocasião e seguindo a ordem de matança dos suínos, até completar os 20 produtores, totalizando 412 amostras.

A coleta de sangue foi realizada através de punção da veia jugular, durante o abate, sendo as amostras dessoradas e estocadas no mesmo dia. Imediatamente após a coleta, o sangue foi transferido para tubos de ensaio, que foram identificados e mantidos em temperatura ambiente até a retração do coágulo. As amostras foram, então, transportadas em caixas isotérmicas para a Universidade Federal Rural do Semi-Árido (UFERSA) onde foram centrifugadas por 10 minutos a 3000 rpm para a obtenção do soro. Depois foram aliquotadas e estocadas a $-20^{\circ} \mathrm{C}$ até a realização dos testes sorológicos.

Paralelamente, foram visitadas as propriedades de origem dos suínos para a realização de inspeção das criações e entrevistas com os produtores, por meio de um roteiro contendo questões abertas e fechadas sobre ambiente, manejo, alimentação, controle sanitário e profilático dos animais, além de dados da ordem humana, social e econômica dos proprietários. Ao final de cada visita/entrevista, foi realizado um trabalho de educação sanitária compreendendo os temas de sanidade e zoonoses dos suínos para com os proprietários, familiares e tratadores.

As amostras foram transportadas para o Laboratório de Brucelose e Leptospirose da Universidade Estadual Paulista "Júlio de Mesquita Filho", Câmpus de Jaboticabal, onde se procedeu às análises, que compreenderam o teste do antígeno acidificado tamponado (AAT), seguido da reação de fixação de complemento (RFC) para as amostras positivas no primeiro teste.

0 AAT foi realizado conforme recomendado no Manual do Programa Nacional de Controle e Erradicação da Brucelose e Tuberculose Animal (Brasil 2006). 0 método consiste em colocar 0,03 $\mathrm{mL}$ do soro em contato com $0,03 \mathrm{~mL}$ do antígeno, em uma placa de vidro quadriculada, seguido de leve homogeneização e mantendo a placa em movimentos rotatórios e constantes até o momento da leitura, que é feita após quatro minutos de reação, observando, com o auxílio de uma caixa com luz (ou aglutinoscópio), a ocorrência dos grumos de aglutinação. 0 antígeno empregado nessa técnica foi preparado com Brucella abortus amostra 1119/3, na concentração de 8,0\% de volume celular, corado com rosa de Bengala, $\mathrm{pH} 3,65$.

A reação de fixação de complemento (RFC) foi realizada utilizando o mesmo antígeno empregado no teste de soroaglutinação lenta em tubos, também preparado com Brucella abortus amostra 1119/3. A diluição do antígeno foi determinada por titulação em bloco, escolhendo-se como diluição a metade da diluição de reatividade ótima. Como complemento foi usada uma mistura de soros sanguíneos de várias cobaias. Esse complemento foi titulado como descrito por Alton et al. (1988), usando 20 vezes o volume empregado na microtécnica, para determinar o volume que continha uma unidade hemolítica 50\%. Para uso no teste, o complemento foi diluído de modo a conter 5 unidades hemolíticas 50\%. Foi empregado sistema hemolítico formado por suspensão de hemácias de carneiro padronizada em espectrofotômetro para a concentração de $0,95 \mathrm{~g}$ de hemoglobina por $100 \mathrm{~mL}$, acrescida de igual volume de uma suspensão de hemolisina, que consiste de anticorpos de coelho contra hemácias de carneiro, titulada conforme a recomendação de Alton et al. (1988). Considerou-se positivo o soro com pelo menos $25 \%$ de fixação de complemento na diluição 1:4.

Os dados laboratoriais e da entrevista foram digitados em planilha eletrônica, e, após checagem, transferidos para o software estatístico SPSS 17.0 (Statistical Package for the Social Sciences), sendo posteriormente codificados para realização das análises. Diversos grupos foram comparados, obtendo-se odds ratio (OR), intervalos de confiança de 95\%, e significância determinada através do teste do qui-quadrado $\left(\chi^{2}\right)$ e exato de Fisher. Este último, por sua vez, foi utilizado sempre que se verificassem valores com 
frequência esperada inferior a 5.0 nível de significância estabelecido foi o valor de $\mathrm{p}<0,05$.

Para o ajuste das variáveis foi utilizado um modelo de regressão logística para estudar, de forma simultânea, os múltiplos efeitos que poderiam estar envolvidos na prevalência da soropositividade para brucelose. Compuseram esta etapa da análise as variáveis que tiveram relação com a brucelose com valor de $\mathrm{p}<$ 0,20 . Em função do número de variáveis estudadas, inicialmente foram montados modelos logísticos para cada grupo, de acordo com características relevantes aos animais e proprietários. Foram excluídas do modelo logístico as que apresentaram intervalos de confiança de grande amplitude nas estimativas da odds ratio, bem como as que apresentaram colinearidades. Sendo assim, compuseram a análise para o modelo final variáveis com nível de significância de $p<0,10$. Estas, por sua vez, foram reagrupadas em um modelo único e novamente avaliadas pelo método completo de remoção sucessiva das variáveis. Nesta etapa foi utilizado o nível de significância de $p<0,05$. Como medida de qualidade de ajuste de regressão logística foi utilizado o teste de Hosmer e Lemeshow, no qual um $\mathrm{p} \geq 0,05$ indica que o modelo está ajustado.

O projeto de pesquisa foi aprovado pela Comissão de Ética no Uso de Animais (CEUA) da Universidade Federal Rural do Semi-Árido (UFERSA), registrado sob № 02/2013 e Processo № 23091.003915/2012-42 CEUA/UFERSA. Por envolver entrevista com os proprietários dos suínos, o projeto também foi submetido ao Comitê de Ética com Seres Humanos, junto à Comissão Nacional de Ética em Pesquisa do Conselho Nacional de Saúde, via Plataforma Brasil do Ministério da Saúde, com o número de inscrição CAAE (Certificado de Apresentação para Apreciação Ética) 13798813.7.0000.5296. Posteriormente o projeto foi encaminhado ao Comitê de Ética em Pesquisa da Universidade Potiguar, obtendo parecer final favorável № 290.224/2013 CEP/UNP.

\section{RESULTADOS}

Dentre os 412 animais examinados em Mossoró-RN, 107 foram positivos na triagem pelo teste de AAT, com positividade de $26,0 \%$. Na prova confirmatória de fixação de complemento, 72 amostras foram positivas, o que correspondeu a uma prevalência de $17,5 \%$. 0 percentual de confirmação da fixação de complemento quando comparado ao AAT foi de 67,3\% (72/107). Os títulos na fixação de complemento variaram de 1:4 até 1:128 (Quadro 1). Quanto às propriedades rurais produtoras de suínos pesquisadas, em $55 \%(11 / 20)$ existia pelo menos um animal positivo para Brucella, e a prevalência nestas oscilou de 6,7\% a 80,0\%.

Em primeira análise, a única variável relacionada aos proprietários que teve associação com a brucelose foi a escolaridade (nenhum ou até quatro anos de estudo). Dentre as variáveis ligadas aos animais e ao ambiente tiveram associação a faixa etária jovem, o regime de semiconfinamen-

\section{Quadro 1. Resultado da fixação de complemento para brucelose, de acordo com os títulos observados, em amostras de suínos de Mossoró/RN, 2013}

\begin{tabular}{ccc}
\hline Título FC & $\mathrm{n}$ & $\%$ \\
\hline 4 & 11 & 15,3 \\
8 & 07 & 9,7 \\
16 & 12 & 16,7 \\
32 & 14 & 19,4 \\
64 & 08 & 11,1 \\
128 & 20 & 27,8 \\
TOTAL & 72 & 100
\end{tabular}

to, a alimentação que incluía lavagem, o contato com suínos de outros criatórios, e a presença de bovinos, caprinos/ovinos, cães, urubus e ratos. Algumas variáveis analisadas se mostraram como fator de proteção, sendo estas a presença de apenas um trabalhador na criação, o uso de água tratada na dessedentação dos animais e o saneamento das instalações quando considerado bom ou regular (Quadro 2).

Quadro 2. Resultados dos exames de brucelose em suínos de Mossoró / RN, 2013, de acordo com as variáveis pesquisadas, e os respectivos valores do odds ratio, intervalo de confiança e significância estatística

\begin{tabular}{|c|c|c|c|c|c|}
\hline Variável & + & - & OR & IC- $95 \%$ & $\mathrm{p}$ \\
\hline \multicolumn{6}{|l|}{ Sexo dos animais } \\
\hline Machos & 39 & 153 & 1,444 & $0,867-2,406$ & 0,157 \\
\hline Fêmeas & 33 & 187 & 1 & & \\
\hline \multicolumn{6}{|l|}{ Faixa etária dos animais } \\
\hline Jovem & 50 & 176 & 2,118 & $1,228-3,651$ & $0,006^{*}$ \\
\hline Adulto & 22 & 164 & 1 & & \\
\hline \multicolumn{6}{|c|}{ Escolaridade dos proprietários } \\
\hline 0 a 4 anos de estudo & 61 & 246 & 2,119 & $1,069-4,202$ & $0,029 *$ \\
\hline $5+$ anos de estudo & 11 & 94 & 1 & & \\
\hline \multicolumn{6}{|l|}{ Total suínos } \\
\hline$<100$ & 12 & 81 & 0,640 & $0,328-1,247$ & 0,187 \\
\hline$\leq 100$ & 60 & 259 & 1 & & \\
\hline \multicolumn{6}{|l|}{ Sistema de criação } \\
\hline Extensivo & 0 & 12 & 0,333 & $0,018-5,898$ & 0,6090 \\
\hline Semiconfinamento & 56 & 191 & 2,510 & $1,381-4,563$ & $0,002^{*}$ \\
\hline Confinamento & 16 & 137 & 1 & - & - \\
\hline \multicolumn{6}{|l|}{ Número de trabalhadores } \\
\hline 1 & 08 & 132 & 0,197 & $0,092-0,424$ & $0,000^{*}$ \\
\hline $2+$ & 64 & 208 & 1 & & \\
\hline \multicolumn{6}{|l|}{ Instalações } \\
\hline Madeira e terra & 50 & 266 & 0,632 & $0,360-1,111$ & 0,109 \\
\hline Alvenaria + madeira e terra & 22 & 74 & 1 & & \\
\hline \multicolumn{6}{|l|}{ Alimentação com lavagem } \\
\hline Sim & 69 & 269 & 6,071 & $1,856-19,858$ & $0,001^{*}$ \\
\hline Não & 03 & 71 & 1 & & \\
\hline \multicolumn{6}{|l|}{ Água tratada } \\
\hline Sim & 03 & 113 & 0,087 & $0,027-0,284$ & $0,000^{*}$ \\
\hline Não & 69 & 227 & 1 & & \\
\hline \multicolumn{6}{|l|}{ Saneamento } \\
\hline Bom & 0 & 53 & 0,023 & $0,0014-0,392$ & $0,000^{*}$ \\
\hline Regular & 25 & 167 & 0,3822 & $0,223-0,6552$ & $0,0004^{*}$ \\
\hline Ruim & 47 & 120 & 1 & - & - \\
\hline \multicolumn{6}{|l|}{ Carcaças } \\
\hline Enterra & 30 & 53 & 3,868 & $2,226-6,722$ & $0,000^{*}$ \\
\hline Não enterra & 42 & 287 & 1 & & \\
\hline \multicolumn{6}{|l|}{ Contato outros suínos } \\
\hline Sim & 57 & 107 & 8,275 & $4,482-15,276$ & $0,000^{*}$ \\
\hline Não & 15 & 233 & 1 & & \\
\hline \multicolumn{6}{|l|}{ Bovino } \\
\hline Sim & 30 & 94 & 1,869 & $1,105-3,161$ & $0,018^{*}$ \\
\hline Não & 42 & 246 & 1 & & \\
\hline \multicolumn{6}{|l|}{ Caprino e ovino } \\
\hline Sim & 54 & 145 & 4,034 & $2,270-7,171$ & $0,000^{*}$ \\
\hline Não & 18 & 195 & 1 & & \\
\hline \multicolumn{6}{|l|}{ Cães } \\
\hline Sim & 61 & 226 & 2,797 & $1,417-5,523$ & $0,002 *$ \\
\hline Não & 11 & 114 & 1 & & \\
\hline \multicolumn{6}{|l|}{ Urubu } \\
\hline Sim & 41 & 41 & 9,645 & $5,458-17,044$ & $0,000^{*}$ \\
\hline Não & 31 & 299 & 1 & & \\
\hline \multicolumn{6}{|l|}{ Ratos } \\
\hline Sim & 64 & 217 & 4,535 & $2,105-9,770$ & $0,000^{*}$ \\
\hline Não & 08 & 123 & 1 & & \\
\hline
\end{tabular}

$\bar{*}$ Significância estatística $(\mathrm{p}<0,05)$; OR - Odds ratio; IC- 95 - Intervalo de confiança de 95\%. 
Após análise multivariada, quando feito o teste de Hosmer e Lemeshow que mostrou boa adequação do modelo, os fatores de risco que continuavam a influenciar a ocorrência da doença foram a presença de ratos nas criações, o contato com bovinos e a faixa etária jovem dos animais (Quadro 3).

\begin{tabular}{lccc}
$\begin{array}{l}\text { Quadro 3. Variáveis que permaneceram no modelo final da } \\
\text { análise multivariada para os casos de brucelose em suínos } \\
\text { de Mossoró/RN, 2013 }\end{array}$ \\
\hline Variável & Odds ratio & IC - 95\% & p \\
\hline Presença de ratos & 7,416 & $3,261-16,868$ & 0,000 \\
Presença de bovinos & 3,212 & $1,774-5,814$ & 0,000 \\
Faixa etária & 2,292 & $1,299-4,043$ & 0,004
\end{tabular}

IC-95 = Intervalo de confiança de 95\%.

\section{DISCUSSÃO}

Analisando o resultado encontrado, é pertinente considerar que uma prevalência de $17,5 \%$ seja alta, visto que foi superior ao encontrado pela maioria dos autores no Brasil, como nos achados de Braga et al. (2013) em suínos do Piauí (1,04\%), Rosa, Garcia e Megid (2012) em suínos de abatedouro provenientes da região central de São Paulo $(2,7 \%)$, Jesus et al. (2010) em granja comercial do Rio de Janeiro $(12,8 \%$ entre matrizes e reprodutores e $8,9 \%$ em todo o plantel), Aguiar et al. (2006) em suínos da agricultura familiar de Rondônia (0,9\%), Ribeiro (2005) em animais da Região Metropolitana de Natal/RN (11,7\%), Barthasson (2005) em suínos de Goiás criados extensivamente, provenientes de criações de subsistência (1,7\%), e Matos et al. (2004) em granjas comerciais do mesmo estado $(2,5 \%)$. Verificou-se também que, de maneira inversa, apenas nos estudos realizados por Ribeiro et al. (2001) em granjas comerciais de Pernambuco e Freitas et al. (2001) em suínos de abate clandestino no Pará, foram observados percentuais superior ao encontrado, sendo de $31,8 \%$ e $42,2 \%$, respectivamente. No entanto, convém salientar que a prevalência varia de acordo com a região do país estudada, as condições de manejo e o tipo de exploração animal.

A presença de apenas um trabalhador na lida com os animais revelou-se como fator de proteção. Vale destacar que a redução no número de trabalhadores é uma importante medida sanitária, uma vez que, quanto mais pessoas em contato com os animais, maiores as chances de ocorrência de doenças, pois o homem têm o potencial de transmitir patógenos aos suínos, principalmente de forma mecânica, conforme mencionou Fávero et al. (2003).

O uso de água tratada na dessedentação dos animais se mostrou um fator de proteção. Do contrário, a água não tratada ou contaminada pode funcionar como uma das principais vias de transmissão de patógenos aos animais domésticos, constituindo um fator importante, tanto para a economia, por poder acarretar prejuízos econômicos, como para a saúde pública, pois muitos agentes podem ser transmitidos ao ser humano (Amaral et al. 2005). Barcellos et al. (2009) reforçam que a água a ser usada para bebida dos animais deve ser tratada e estar potável, atendendo aos mesmos parâmetros indicados para a água de consumo humano.

O saneamento das instalações quando considerado bom ou regular também foi considerado fator de proteção. Sabe- -se que, o saneamento deficiente favorece a contaminação de alimentos e água por descargas vulvares, fetos abortados e membranas fetais, o que pode representar risco na epidemiologia da brucelose nas criações (Aparício 2013).

Estudos sobre os principais fatores de risco associados com a brucelose suína no Brasil são escassos. De acordo com Aparício (2013), os principais riscos relacionados à transmissão da brucelose nesta espécie animal são a introdução de animais infectados nas criações, o contato com reservatórios naturais e inseminação artificial com sêmen de animal infectado. No entanto, estes não foram observados na presente pesquisa.

No nosso estudo, chamou atenção a associação da ocorrência de positividade para Brucella com a presença de roedores, o que demonstra a existência de falhas no aspecto sanitário das criações. 0 achado merece atenção especial, uma vez que, em geral, os roedores estão relacionados a problemas de higienização das criações, podendo estes entrarem em contato com materiais contaminados e depois contaminar o alimento e a água dos animais. 0 exposto é reforçado por Lau (1997), mencionando que a disseminação da brucelose através de roedores deve ser considerada.

Os resultados apontaram para a presença de bovinos influenciando a ocorrência da brucelose suína. Alguns autores relatam a possibilidade de transmissão cruzada da brucelose entre estas duas espécies de produção, a exemplo de Brucella abortus, que pode acometer suínos e da $B$. suis, que pode infectar bovinos (Roxo et al. 1996, Acha \& Szyfres 2001, Aparício, 2013, Godfroid et al. 2013).

A faixa etária jovem dos animais foi outro fator de risco encontrado, o que levanta a possibilidade de transmissão da brucelose por resíduo de alimento contaminado ou durante a fase intra-uterina e amamentação, e não via sexual, conforme mencionou Jesus et al. (2010) em seus achados. Os autores apontaram para uma maior concentração de suínos reagentes à brucelose na categoria de animais jovens.

Convém destacar que alguns problemas eram comuns em todas as propriedades estudadas, independentemente de os suínos serem positivos ou negativos para brucelose. Presença de moscas, não segregação dos animais por faixa etária, manejo reprodutivo sem controle (monta natural), ausência de área destinada para animais em quarentena ou doentes, ausência de assistência veterinária regular e carência de informações por parte dos proprietários (ausência de capacitação em sanidade ou zoonoses de suínos e inexistência de conhecimento sobre brucelose) foram achados regulares, mas não incluídos como objeto de análise.

0 presente trabalho confirmou a circulação do agente infeccioso da brucelose com elevada prevalência entre os animais e nas propriedades pesquisadas, mesmo não tendo sido observados animais sintomáticos durante as visitas, o que sugere a necessidade de adoção de medidas de prevenção e controle, principalmente direcionadas aos fatores de risco identificados, com o objetivo de evitar perdas econômicas e transmissão do agente ao ser humano.

\section{REFERÊNCIAS}

Acha P.N. \& Szyfres B. 2001. Zoonosis y Enfermidades Transmisibles Comunes al Hombre y a los Animales. Vol.1. Bacteriosis y Micosis. $3^{\mathrm{a}}$ ed. Organización Panamericana de la Salud, Washington, p.28-56. 
Aguiar D.M., Cavalcante G.T., Dib C.C., Villalobos E.M.C., Cunha E.M.S., Lara M.C.C.S.H., Rodriguez C.A.R., Vasconselos S.A., Moraes Z.M., Labruna M.B., Camargo L.M.A. \& Gennari S.M. 2006. Anticorpos contra agentes bacterianos e virais em suínos de agricultura familiar do município de Monte Negro, RO. Arqs Inst. Biológico, São Paulo, 73(4):415-419.

Alton G.G., Jones L.M., Angus R.D. \& Verger J.M. 1988. Techniques for the brucellosis laboratory. Institut Nacional de la Recherche Agronomique, Paris. 190p.

Amaral L.A., Rossi Jr O.D., Nader Filho A., Souza M.C.I. \& Isa H. 2005. Água utilizada em suinocultura como fator de risco à saúde humana e animal. Ars Vet. 21(1):41-46.

Aparicio E.D. 2013. Epidemiología de la brucelosis causada por Brucella melitensis, Brucella suis y Brucella abortus en animales domésticos. Rev. Scient. Tech. Off. Int. Epiz. 32(1):43-51.

Barcellos D.E.S.N., Marques B.M.F.P.P., Mores T.J., Centenaro F. \& Sobestiansky J. 2009. Uso de perfis sorológicos e bacteriológicos em suinocultura. Acta Scientiae Veterinariae 37(Suppl.1):s117-s128.

Barthasson D.L. 2005. Perfil sanitário de suínos de criações extensivas do Estado de Goiás. Dissertação de Mestrado em Ciência Animal, Universidade Federal de Goiás, Goiânia. 84p.

Braga J.F.V., Teixeira M.P.F., Franklin F.L.A.A., Souza J.A.T., Silva S.M.M.S. \& Guedes R.M.C. 2013. Soroprevalência de pseudorraiva, peste suína clássica e brucelose em suínos do estado do Piauí. Arq. Bras. Med. Vet. Zootec. 65(5):1321-1328.

Brasil 2009. Manual de Legislação: Programas Nacionais de Saúde Animal do Brasil, Ministério da Agricultura, Pecuária e Abastecimento (MAPA/ SDA/DAS), Brília. 440p.

Brasil 2006. Programa Nacional de Controle e Erradicação da Brucelose e Tuberculose (PNCEBT). Manual Técnico, Ministério da Agricultura, Pecuária e Abastecimento (MAPA/SDA/DAS), Brasília. 188p.

Fávero J.A. 2003. Sistema de Produção de Suínos. Centro Nacional de Pesquisa de Suínos e Aves, Empresa Brasileira de Pesquisa Agropecuária, Concórdia, SC. Versão eletrônica. Disponível em <http:www.cnpsa.embrapa.br> Acesso em 6 dez. 2013.

Freitas J.A., Galindo G.A.R., Santos E.J.C., Sarraf K.A. \& Oliveira J.P. 2001. Risco de brucelose zoonótica associado a suínos de abate clandestino. Revta Saúd. Publ. 35:101-102.
Godfroid J., Garin-Bastuji B., Saegerman C. \& Blasco J.M. 2013. Brucellosis in terrestrial wildlife. Rev. Scient. Tech. Off. Int. Epiz. 32(1):27-42.

IBGE 2012a. Censo Demográfico 2010: resultados gerais da amostra. Instituto Brasileiro de Geografia e Estatística, Rio de janeiro.

IBGE 2012b. Produção da Pecuária Municipal. Instituto Brasileiro de Geografia e Estatística, Rio de Janeiro, 40:1-71.

Jesus V.L.T., Pereira R.C.G., Meireles G.S., Rodrigues J.S., Jorge J.L.B.P. \& Flausino W. 2010. Brucelose suína no Estado do Rio de Janeiro. Rev. Bras. Med. Vet. 32(2):101-104.

Lau H.D. 1997. Brucelose: uma ameaça para a pecuária em áreas de fronteira agrícola da Amazônia. Recomendações Básicas no 33, Embrapa Amazônia Oriental, Belém, PA.

Mathias L.A. 2008. Brucelose animal e suas implicações em saúde pública. Biológico, São Paulo, 70(2):47-48.

Matos M.P.C.M., Sobestiansky J., Pôrto R.N.G. \& Meirinhos M.L.G. 2004. Ocorrência de anticorpos para Brucella sp. em soros de matrizes suínas de granjas que abastecem o mercado consumidor de Goiânia, Estado de Goiás, Brasil. Ciênc. Anim. Bras. 5(2):105-108.

OIE 2014. OIE - Listed diseases, infections and infestations in force in 2014. Disponível em <http://www.oie.int/animal-health-in-the-world/ oie-listed-diseases-2014> Acesso em 31 jan. 2014.

Plumb G.E., Olsen S.C. \& Buttke D. 2013. Brucellosis: 'One Health' challenges and opportunities. Rev. Scient. Tech. Off. Int. Epiz. 32(1):271-278.

Ribeiro T.C.F.S. 2005. Aspectos produtivos da suinocultura e estudo epidemiológico da brucelose suína na região metropolitanade Natal, RN. Tese de Doutorado em Ciência Veterinária, Universidade Federal Rural de Pernambuco, Recife. 64p.

Ribeiro T.C.F., Mota R.A., Costa A.N., Lima E.T. \& Castro Júnior I.F. 2001. Inquérito soroepidemiológico da brucelose suína em granjas comerciais da Zona da Mata de Pernambuco. Ciênc. Anim. Bras. 11(2):65-71.

Rosa D.C., Garcia K.C.O.D. \& Megid J. 2012. Soropositividade para brucelose em suínos em abatedouros. Pesq. Vet. Bras. 32(7):623-626.

Roxo E., Bersano J.G. \& Portugal M.A.S.C. 1996. Brucella suis em diversas espécies de animais numa mesma propriedade rural. Arqs Inst. Biológico, São Paulo, 63(1):11-14.

Thrusfield M.V. 2004. Epidemiologia Veterinária. 2ª ed. Roca, São Paulo. 556 p. 